\title{
Two Flexible Loops in Subtilisin-like Thermophilic Protease, Thermicin, from Thermoanaerobacter yonseiensis
}

\author{
Hyeung Jin Jang, Chang-Hun Lee, Weontae Lee and Yu Sam Kim* \\ Department of Biochemistry, College of Science, Protein Network Research Center, Yonsei University, Seoul 120-749, Korea
}

Received 28 May 2002, Accepted 13 August 2002

\begin{abstract}
A gene that encodes a thermostable protease, coined thermicin, has been isolated from Thermoanaerobacter yonseiensis that is expressed and characterized in $E$. coli.. In order to elucidate the molecular characteristics on thermostability of the enzyme, molecular modeling and mutagenesis technology were applied. In the modeling structure, the structural core, including the active site, was well conserved; whereas, the two loop regions were unique when compared to thermitase. The mutant enzyme with the small loop deleted (D190-I196), based on modeling structural information, showed identical enzyme activity. However, when the large loop was deleted (P233-P244), a little lower $K_{m}$ and even a lower kcat was found. This indicates that the large loop could influence catalytic activity. However, the unfolding temperature $\left(T_{m}\right)$, which was determined by a differential-scanning calorimetry for the mutant enzyme deleted the small loop, was $96^{\circ} \mathrm{C}$. This is $14^{\circ} \mathrm{C}$ lower than that for the parent thermicin. These results suggest that the small loop may play a role in maintaining the proper folding of the enzyme at high temperatures, whereas the large loop might be related to catalysis.
\end{abstract}

Keywords: Thermicin, Thermoanaerobacter yonseiensis, Thermophilic protease

\section{Introduction}

Some organisms are able to grow at temperatures above the boiling point of water, where the proteins from the organism are extremely stable at high temperatures. Elucidation of the molecular-basis thermostability of the proteins is important, not only to the comprehensive understanding of how a protein keeps its native conformation, but also to the development of

*To whom correspondence should be addressed.

Tel: 82-2-2123-3448; Fax: 82-2-392-3488

Email.yskim@yonsei.ac.kr enzyme applications in industry. To identify the key factors that are responsible for the increased thermostability, an initial attempt was made to conduct the multiple amino acid sequence comparisons of homologous enzymes that are isolated from various organisms with different growth temperatures (Argos et. al., 1979). Extensive structural comparisons led to the conclusion that the overall conformation of each structure is quite similar to that of its counterpart proteins from mesophilic organisms; only slight differences in structure (including small deletions and/or insertions) make thermophilic proteins more stable than their mesophilic counterparts (Imada et al., 1991; Day et al., 1992; Yip et al. 1995; Wallon et al., 1997). However, the proposed factors that are responsible for thermostability include the following: number of ion pairs (Perutz et al., 1975; Yip et al., 1995; Vogt et al., 1997), number and type of hydrogen bonds per residue (Shortle et al., 1992), amount and type of solvent accessible surface area (Chan et al., 1995), amino acid composition (Fleming et al., 1997), hydrophobic core size (Eriksson et al., 1992), cavity size (Eriksson et al., 1992), and multimer association regions of the protein (Wallon et al., 1997). These suggestions on thermostability have sometimes been controversial (Kim et al.). An increased number of ion pairs appeared to be the only identifiable difference that could lead to thermostability in a thermophilic citrate synthase (Russel et al., 1997); whereas, in psychrophilic (cold-active) citrate synthase, an increased number of ion pairs was known to cause an increase in the resistance to low temperature denaturation (Russel et al., 1998).

In order to understand the roles of particular side chains in proteins, specific sites of some proteins were substituted for other amino acids (Yutani et al., 1987; Matsumura et al., 1988; Lim et al., 1989; Sandberg et al., 1991). This raises the possibility that even a single amino acid substitution may considerably increase the thermostability of the protein, although the chance to significantly increase the protein stability depends on the overall structure of a protein, as well as the local environment of the side chain residues. Therefore, a systematic mutational analysis of the proteins with the three- 
dimensional (3-D) structural information is essential for discovering the correlation between the structure and the stability of proteins.

In a previous work (Jang et al., submitted), we presented the cloning and expression for a gene that encodes a novel thermostable protease, thermicin, from the anaerobic bacteria. Interestingly thermicin contains neither cysteine residues in the mature enzyme nor the calcium-binding motif, which indicates that there might be other factors beside those that are related to thermostability that were previously mentioned.

In this paper, we report that thermicin has two unique loops that are responsible for thermostability and catalytic activity.

\section{Materials and Methods}

Molecular modeling The homology modeling of thermicin was based on the sequence alignment of subtilisin of both the firefly thermitase (Teplyakov et al., 1989) and subtilisin of Bacillus lentus. using the FASTA (http://www2.ebi.ac.uk/fasta3/) program. The sequence alignment for the structurally-conserved region was performed by structural data that was extracted from the X-ray coordinates of firefly thermitase (PDB code: 1THM) and subtilisin of Bacillus lentus (PDB code: 1ST3). The pair-wise sequence homologies of these two templates against Thermicin were $37.7 \%$ and $39.9 \%$, respectively. The PredictProtein server at EMBL (http:// www.embl-heidelberg.de/predictprotein/predictprotein.html) predicted the secondary structures of thermicin. The initial template structures of thermicin were generated only for heavy atoms. Combining the use of conjugate-gradient energy minimization and molecular dynamics calculations in the MODELLER $(<$ biblio $\rangle$ ) program further optimized the modeling structures. Structurally-variable regions were engineered by combining the use of the PDB coordinate-searching and fragment-fitting routine, and was further relaxed by 1000 steps of conjugate-gradient energy minimization until its energy derivation reached $0.001 \mathrm{kcal} / \mathrm{mol}$. Molecular dynamic simulation of $10 \mathrm{ps}$ at $298 \mathrm{~K}$ was also performed in the MODELLER program. After all of the coordinates were assigned, a conformational search for side chains were performed using the side chain rotamer library. In addition, local structure refinement procedures were also incorporated for each structural segment by successive use of energy minimization and molecular dynamics simulations. Regulating the distortions of bonds and angles finished all of the local refinements, including energy minimizations. Distance-dependent dielectric terms for mimicking the solvent effects were applied for the electrostatic energy calculations. The final thermicin structure was evaluated by the PROCHECK (Laskowski et al., 1993), PROSA (Sippl, 1993) and WHATIF (Vriend and Sander, 1993) programs.

Construction of expression plasmids The deletion of the two loops was performed by the following: polymerase chain reaction (PCR) with oligonucleotide primers, the primer for small loop deletion (L2-2) D190 I196 (DKRT PDI) 5'-G GTA GGA GCA GTG GAC GAA GAC GAC GAA GTA GC -3' \& complementary anti-sense primer, the primer for long loop deletion (L1-3) P233 P244 (PFGAD EIMIN KP) 5'-CA GCT TCT GGA AAT GTG * TAC AGG AGC GCC ACA GG 3 \& complementary anti- sense primer and primer for long and small loop deletions (LL12) 5'G GTA GGA GCA GTG GAC * GAA GAC GAC GAA GTA GC3', complementary anti-sense primer, and 5'-CA GCT TCT GGA AAT GTG * TAC AGG AGC GCC ACA GG-3', complementary anti-sense primer, respectively, using a Gene Amp PCR system 2400 (Perkin-Elmer Applied Biosystems, Foster City, USA). The asterisks indicate the locations of the deletion sites. The pQEX1 (Jang et al., submitted) that contained the wild-type thermicin gene was used as a template DNA for deletion mutagenesis. The mutations were confirmed with a Model 310 DNA sequencer (Perkin-Elmer Applied Biosystems) using dideoxy chain termination sequencing. The resultant plasmids that carried the mutant thermicin genes (L1-3 and L2-2) were constructed in E. coli DH5a, and designated as pL1-3 and pL2-2, respectively. These plasmids were then introduced into $E$. coli M15 (pREP4) by heat shock.

Preparation of mutant enzymes The resulting plasmids were designated pQEXI, pL1-3, and pL2-2. The thermicin and mutant enzymes were expressed in E. coli M15 (pREP4) as previously described (Jang et al., submitted). Thermicin and mutant enzymes from E. coli M15 (pREP4/pQEXI, pL1-3, and pL2-2) were purified by Ni-NTA affinity chromatography in a column of Ni-NTA Kits (Novagen). This was followed by anion exchange chromatography and SP Sepharose column (Amersham Phamacia Biotech, Uppsala, Sweden) (Jang et al., submitted) that yielded purified thermicin as assayed by SDS-PAGE. The enzyme concentration was determined using a BCA assay (Bio-Rad, Richmond, USA). The enzyme concentration in the reaction assays was between 0.5 and $0.75 \mu \mathrm{g} /$ $\mathrm{mL}(7-10 \mathrm{nM})$. In all of the experiments where the rates were compared, the same enzyme preparation with the same enzyme concentration was used.

Enzyme assay The hydrolysis of benzyloxycarbonyl-glycylprolyl-p-nitroanilide (Z-Gly-Pro-pNA) and several other substrates was monitored with a spectrophotometer (Shimadzu UV160A and Beckman DU640). The initial hydrolysis rate of all of the substrates was obtained by monitoring the release of the chromophore pNA (p-nitroanaline) at $405 \mathrm{~nm}\left(\varepsilon=9650 \mathrm{M}^{-1} \mathrm{~cm}^{-1}\right.$ was found constant under all conditions in this study). All of the buffers contained $0.1 \mathrm{M} \mathrm{NaCl}$, unless otherwise specified. The methanol concentration in all of the assays was adjusted to $0.228 \mathrm{mM}$ to enhance the solubility of the Z-Gly-Pro-pNA stock solutions. Methanol was found to inhibit thermicin hydrolysis of ZGP noncompetitively; therefore, the Z-Gly-Pro-pNA hydrolysis rate by thermicin in $0 \%$ methanol was extrapolated from the linear plot of rate vs. methanol concentration (data not shown). The $\mathrm{pH}$ of each buffer was adjusted to the desired value at $85^{\circ} \mathrm{C}$. All of the assays were carried out in $20 \mathrm{mM}$ buffers, acetate/acetic acid at $\mathrm{pH} 4.2$ to 4.7, MES (2-[N-morpholino] ethanesulfonic acid) at $\mathrm{pH} 4.8$ to 6.2 , HEPES (N-[2-hydroxyethyl] piperazine-N-2-ethanesulfonic acid) at $\mathrm{pH} \quad 6.3$ to 7.6, TAPS (N-Tris[hydroxymethyl]methyl-3aminopropane sulfonic acid) at $\mathrm{pH} 7.7$ to 8.6 , and CAPS (cyclohexylaminopropane sulfonic acid) at $\mathrm{pH} 8.7$ to 9.3) in the presence of 0.1 or $0.5 \mathrm{M} \mathrm{NaCl}$. All of the aqueous solutions were prepared from deionized water of $>18 \mathrm{M} \Omega$ from a MilliQ system (Millipore, Bedford, MA). The kinetic parameters, $k_{c a t}$ and $K_{m}$, were obtained by non-linear fitting of the data to the hyperbolic Michaelis-Menten equation. 

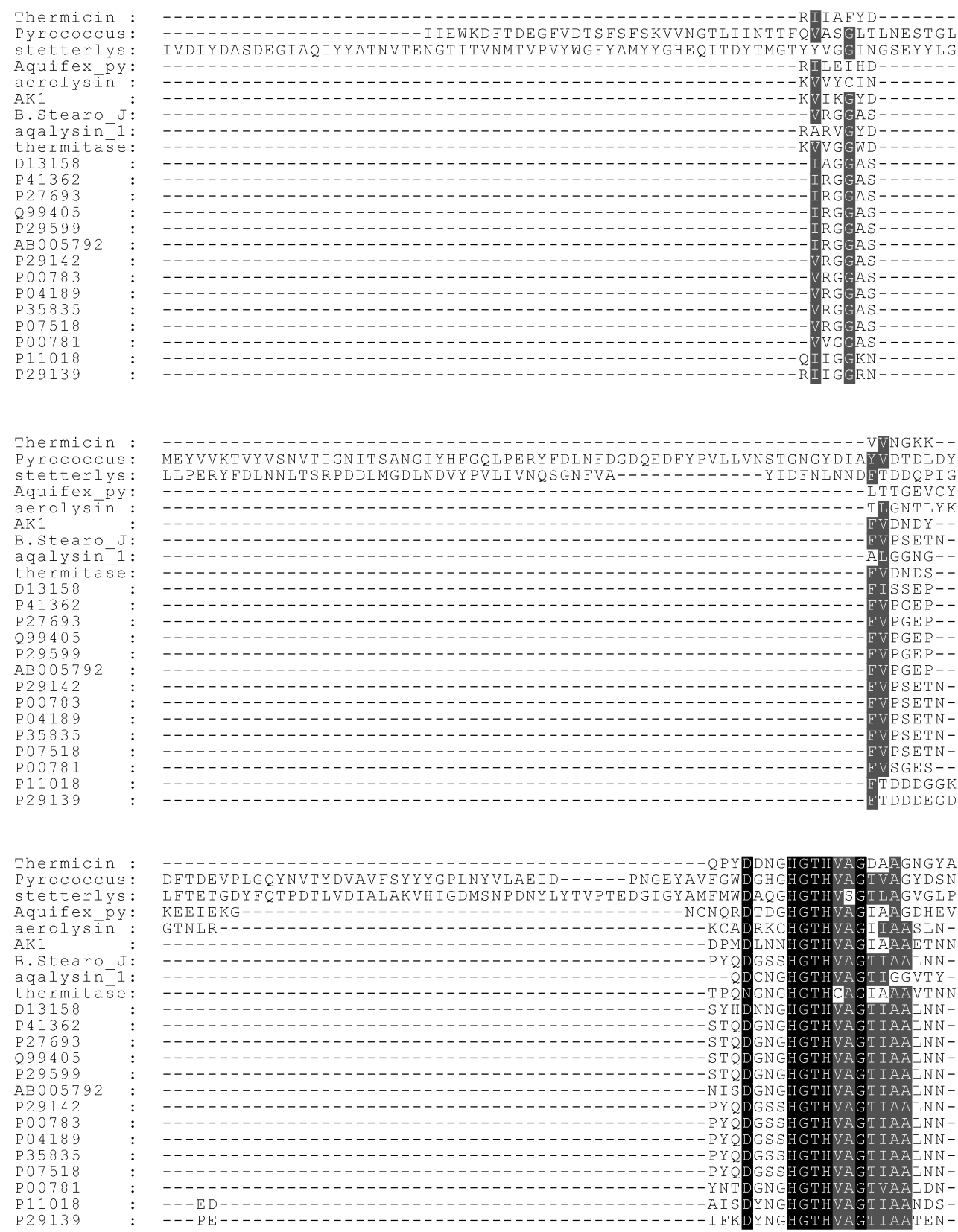

Fig. 1. Continued.

between the $\mathrm{N}$-terminal and $\mathrm{C}$-terminal domains of thermicin is shorter than that of the X-ray structure of thermitase. Interestingly, the structural domains are involved with both a short flexible loop and long loop, which is three $\alpha$-helices that are wrapped by a single two-stranded $\beta$-sheet (Fig. 3). The core active site of thermicin is located on a small cavity that is surrounded by two anti-parallel $\beta$-strands and a single $\alpha$-helix between the $\mathrm{N}$ - and C-terminal domains (Fig. 4).

Preparation of deletion mutant thermicin Expression plasmids of the loop deletion mutants, pQE-2-2, pQE-1-3, and pQE-LL12, were subjected to DNA sequencing in order to confirm that the amino acid deletions had been introduced into these clones. It was confirmed that 7 and 12 amino acid residue deletions had been made during each mutagenesis.

The native and loop-deleted mutant thermicin genes were expressed in E. coli M15 (pREP4). This was followed by purification, partially from the culture fluid.

Catalytic properties of mutant thermicin L1-3 and L2-2 As shown in Table 2, the specific activities toward ZGP as an authentic substrate for subtilisin of the mutant L2-2, thermicin deleted small loop, was essentially equivalent to that of the wild-type enzyme, regardless of whether or not they were 

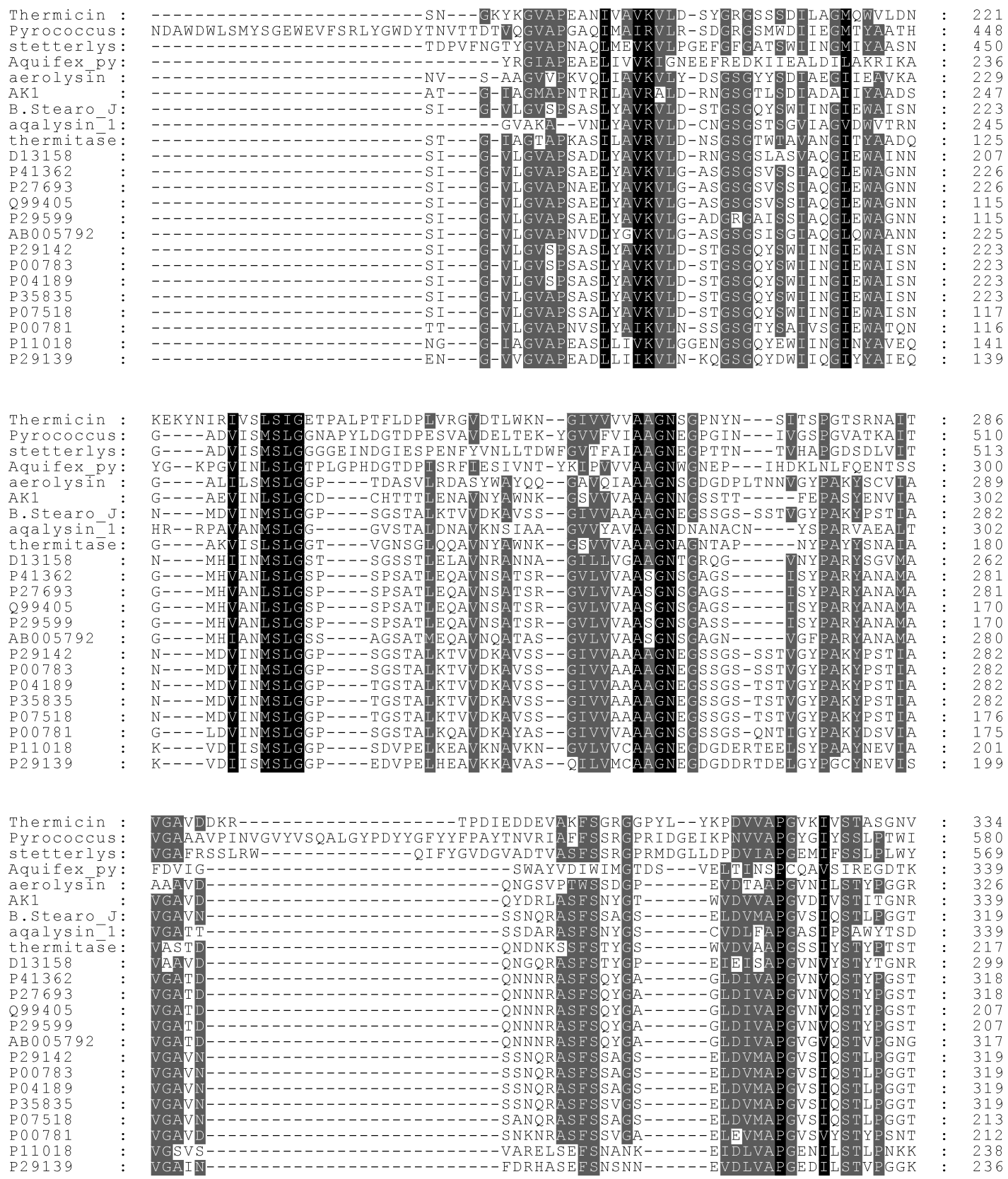

Fig. 1. Continued.

pretreated with $5 \mathrm{mM}$ dithiothreitol for reduction. However, the L1-3 mutant enzyme-deleted long loop showed lower $K_{m}$ and $k_{\text {cat }}$ than that of others, indicating that the long loop may be related to catalytic activity. However, the possibility cannot be ruled out that the alteration with artificial substrates may not be equivalent to protein substrates. It has been shown that for some serine proteases, including subtilisin, reduced autolysis leads to an apparent increase in instability (Daniel $e t$ al., 1982; Takagi et al., 1990; Takagi et al., 2000). Subtilisin is irreversibly inactivated through autolysis at elevated temperatures (Wells et. al. 1986; Mitchinson et al., 1989; Takagi et. al. 1990).
Unfolding temperature of the L1-3 and L2-2 mutant thermicin Using differential-scanning calorimetry, an unfolding temperature $\left(T_{m}\right)$ of $96^{\circ} \mathrm{C}$ was measured for the small loop-deletion mutant, which is $14^{\circ} \mathrm{C}$ lower than the $T_{m}$ that was measured for the parent thermicin and the long loopdeleted mutant enzyme (Fig. 5). This result clearly suggests that the small loop in thermicin may play a role, at least partially, in thermostability.

\section{Discussion}

One of the common strategies to enhance the thermostability 

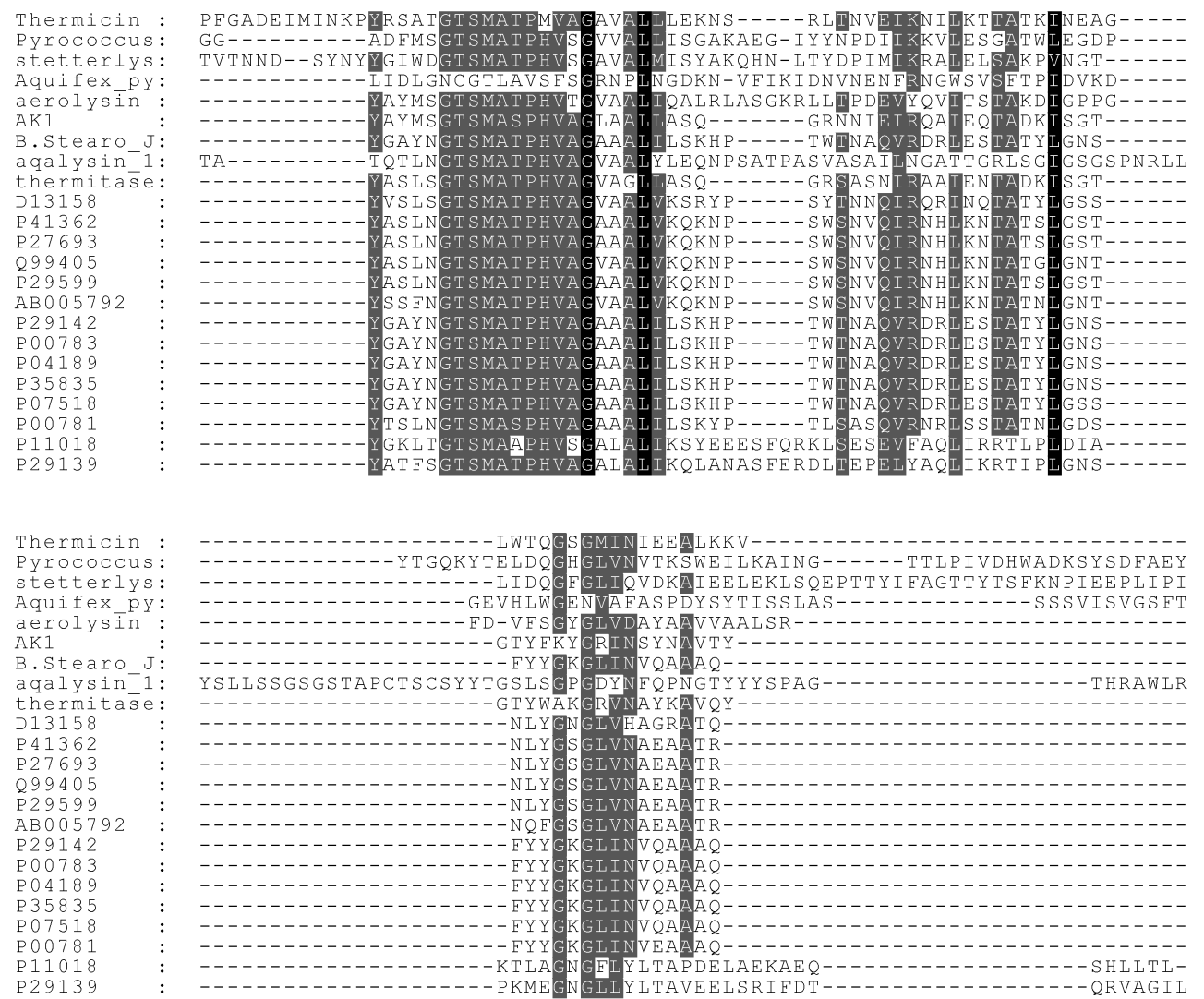

Fig. 1. Continued.

of the enzyme is to introduce disulfide bonds into the protease by SDM. Introduction of a disulfide bond into the subtilisin $\mathrm{E}$ from Bacillus subtilis resulted in an increase of $4.5^{\circ} \mathrm{C}$ in $T_{m}$ of the mutant enzyme, but there was no change in its catalytic efficiency (Takagi et al., 1990). However, the properties of the mutant enzyme were found to revert to those of the wild-type enzyme. Enhanced stability of subtilisin was observed as a result of the mutations of Asn109 and Asn218 to Ser. The analog that contained both mutations showed an additive effect on thermal stability. Thermostability of the alkaline protease from Aspergillus oryzae is important because of its extensive use in manufacturing soy sauce. The optimal temperature of the wild-type enzyme was enhanced from 51 to $56^{\circ} \mathrm{C}$ by the introduction of a disulfide (Cys 169-Cys 200) bond. Another strategy for improving the stability of the protease was by replacing the polar amino acid groups with the hydrophobic groups. The presence of positively-charged amino acids in the N-terminal turn of a helix is undesirable because of the possibility of repulsive interactions with the helix dipole. Replacement of Lys by Ser or Asp resulted in an increase in the thermostability of the neutral protease from $B$. subtilis in the range of 0.3 to $1.2^{\circ} \mathrm{C}$ (Eijsink et al., 1992).

Our comparison shows the distribution of the amino acid composition of thermophilic and mesophilic proteases. A higher occurrence of charged-amino acids was also observed in the proteins from $T$. yonseiensis. The percentage of aspartate, glutamate, arginine, and lysine of the cloned protease was about $21.6 \%$. This is similar to the value that was found in pyrolysin from Pyrococcus furiosus, and is much higher than the proteases from mesophiles or thermophiles (Table 6). These charged-residues may be a participant in the formation of salt bridges, since the range in surface area is much narrower. The distribution of these structural features does not differ significantly between the mesophilic and thermophilic proteins. Therefore, for proteases, it is not possible to find a structural feature that differentiates thermophiles from mesophiles. This suggests that pairwise comparisons of thermophilic structures to mesophilic structures contain no useful information in uncovering the structural basis of thermostability.

From our comparison of a large group of proteins from the same family, we observed two potential factors in the difference between thermophilic and mesophilic protein stability-the loops at the amino side of the protease from thermophilic bacteria and thermal factors. Both of these observations can be related to molecular flexibility. The deletion of the small loop in the thermicin may allow access to conformations that are destabilizing for thermophilic proteins at high temperatures. Fewer glycyl residues in the thermophilic structures may serve to decrease the flexibility of this region, thereby providing greater stability at higher temperatures (Panasik et al., 2000). Localization of 
Table 1. Comparison of amino acids on the substrate binding site

\begin{tabular}{|c|c|c|}
\hline $\begin{array}{l}\text { Binding } \\
\text { Pocket site }\end{array}$ & $\begin{array}{l}\text { Target } \\
\text { residue }\end{array}$ & Substituted residues \\
\hline $\mathrm{P} 2$ ' & F 204 & $\mathrm{~F}$ or $\mathrm{Y}$ \\
\hline P1' & R 246 & variable \\
\hline $\begin{array}{l}\text { P2'-P1 } \\
\text { lining }\end{array}$ & $\begin{array}{l}\text { A } 162 \\
\text { N } 165 \\
\text { T } 249 \\
\text { S } 252\end{array}$ & $\begin{array}{c}\text { Conserved A or few } \mathrm{S} \\
\text { Highly conserved } \\
\text { T or S, N and V, A, K, Q } \\
\text { Conserved S and few G, V, K }\end{array}$ \\
\hline $\begin{array}{l}\text { P1'-P2 } \\
\text { lining }\end{array}$ & $\begin{array}{l}\text { H } 64 \\
\text { D } 29 \\
\text { T } 30\end{array}$ & $\begin{array}{c}\text { Highly conserved } \\
\text { Highly conserved } \\
\mathrm{T} \text { or D }\end{array}$ \\
\hline P1 & $\begin{array}{ll}\text { T } & 135 \\
\text { G } & 164 \\
\text { S } & 166 \\
\text { T } & 174\end{array}$ & $\begin{array}{c}\text { T or E, P, D, G, N, A etc (variable) } \\
\text { Highly conserved } \\
\text { S or G, D } \\
\text { T or N, S, G, K etc. (variable) }\end{array}$ \\
\hline $\mathrm{P} 2$ & N 62 & $\mathrm{~N}$ or I, L, V, S, H (variable) \\
\hline $\begin{array}{l}\text { P1-P3 } \\
\text { lining }\end{array}$ & S 131 & $\mathrm{~S}$ or $\mathrm{N}$ (Highly conserved) \\
\hline $\begin{array}{l}\text { P2-P3 } \\
\text { lining }\end{array}$ & L 98 & Conserved $\mathrm{L}$ or few $\mathrm{C}, \mathrm{F}$ \\
\hline P3 & $\begin{array}{ll}\text { F } & 101 \\
\text { G } & 102 \\
\text { G } & 133\end{array}$ & $\begin{array}{c}\text { Variable } \\
\text { Variable } \\
\text { Highly conserved }\end{array}$ \\
\hline P4 & $\begin{array}{ll}\text { R } & 103 \\
\text { I } & 109 \\
\text { I } & 132 \\
\text { E } & 134 \\
\text { P } & 136\end{array}$ & $\begin{array}{c}\text { Variable } \\
\text { I or A, V and other hydrophobic residues } \\
\text { I or L, W and other hydrophobic residues } \\
\text { E or many P, G and few S } \\
\text { P or many D, S and variable }\end{array}$ \\
\hline
\end{tabular}

temperature effects in 'hinge regions' between elements of secondary structure are also suggested in the work of Fields and Somero (Fields et al., 1998). They concluded that some lactate dehydrogenases adapted to cold temperatures by increasing the flexibility of small areas in the molecule that affect the mobility of adjacent active-site secondary structural elements. They also observed that the thermostable lactate dehydrogenases have a smaller number of glycines in the loop regions between helices. For eight-stranded $\mathrm{a} / \mathrm{b}$ barrels, it was shown earlier that the loops at the amino-terminal face of the barrel are more important for thermostability than those at the other face (Urfer et al., 1992). While other researchers $(<$ biblio $>)$ have explored the concept of rigidity as a means of adaptation to high temperatures, its role as a general mechanism has not been proven experimentally.

A result from this study also suggests that the mobility of inserted amino acid sequences as loops is important in understanding the difference between mesophilic and

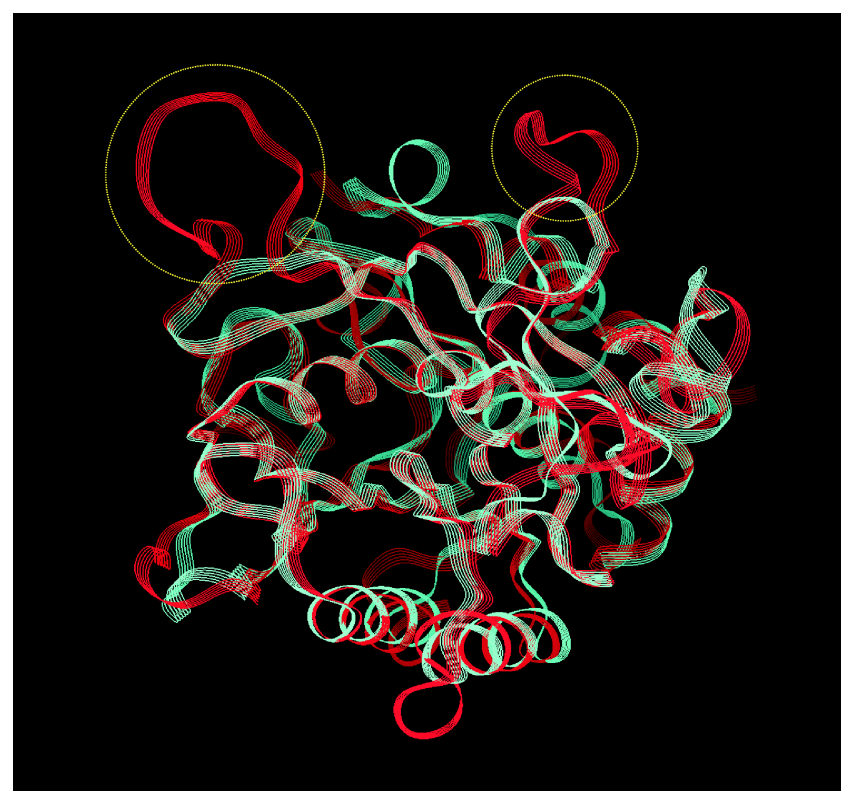

Fig. 2. Ribbon Drawing from the Molecular modeling structure of thermicin (red ribbon). Blue ribbon indicates the structure of thermitase. Two protein structures are superimposed for comparison. Long loop for catalytic activity and short loop for thermostability were enclosed by yellow circles. This structural diagram was produced by the Insight II version 98.0 program (Molecular Simulations Inc.).

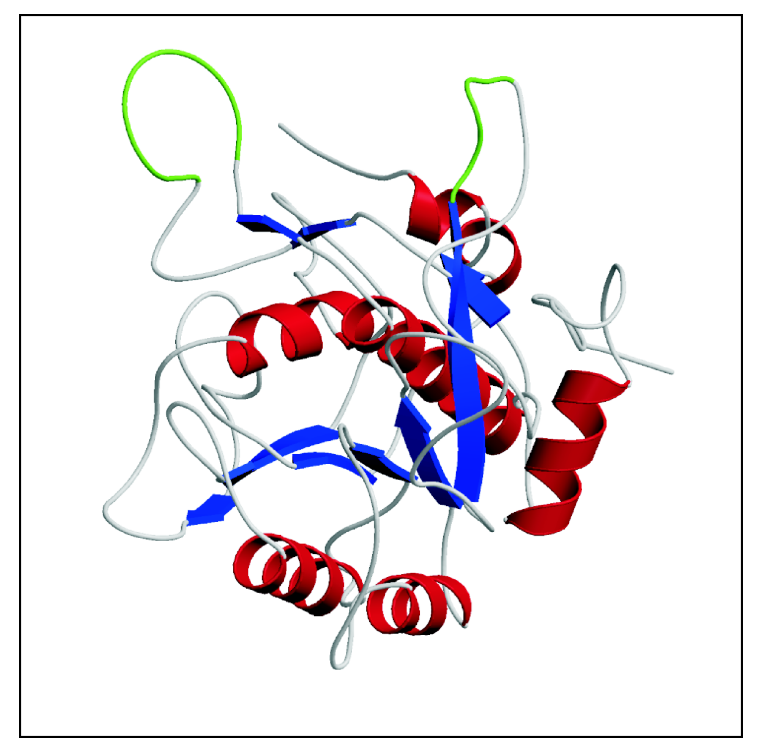

Fig. 3. Schematic Drawing of Simplified modeling structure of thermicin. Red, blue, and green colors indicate $\alpha$-helix, $\beta$-sheet, and loops, respectively. The drawing was produced by the MOLSCRIPT version 2.1 (Kraulis, 1991) and Raster3D version 2.6 (Bacon and Anderson, 1988).

thermophilic structures. The average main chain and side chain thermal factors for the thermophilic structures were found to be consistently higher than for mesophiles. This 


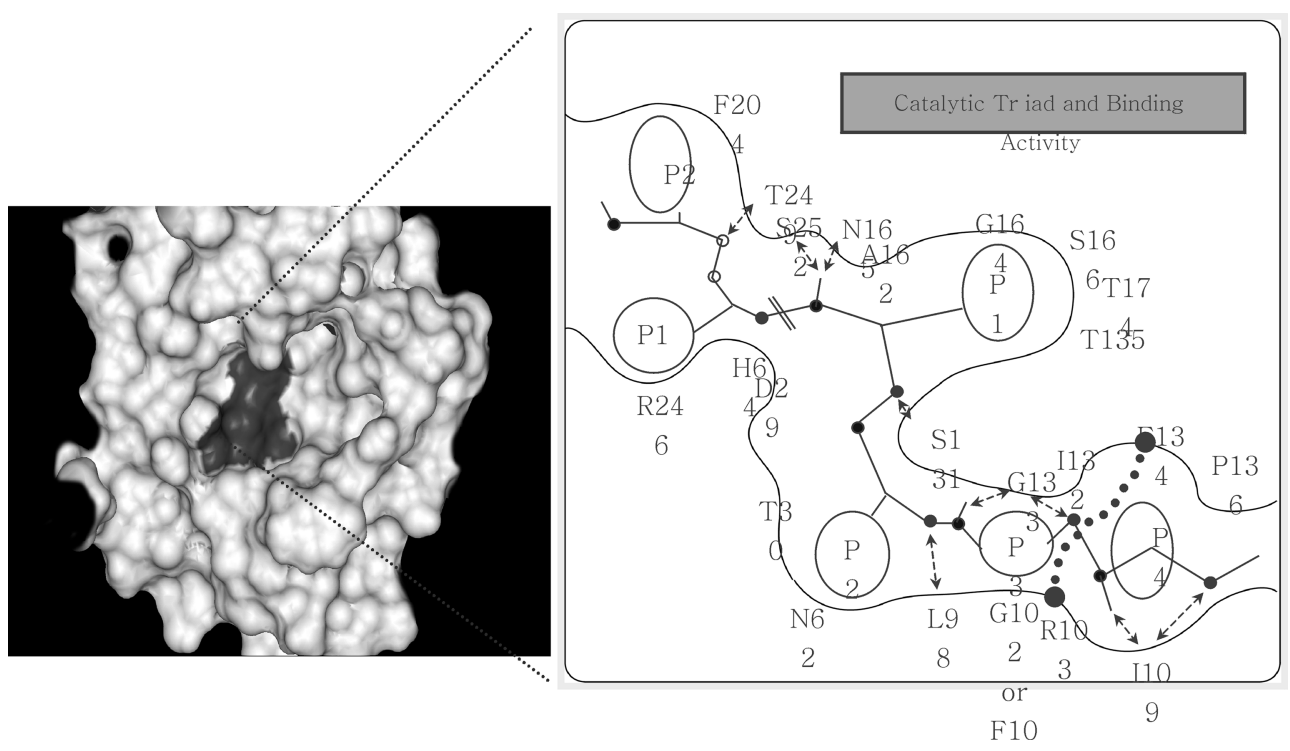

Fig. 4. Location of active site of thermicin, based on modeling structure. Catalytic triads and binding motif are also drawn.

Table 2. Comparison of kinetic parameters for the hydrolysis of synthetic peptide by native and mutant thermicins

\begin{tabular}{cccc}
\hline $\begin{array}{c}\text { Thermicin and } \\
\text { loop deletion mutants }\end{array}$ & $K_{m}(\mu \mathrm{M})$ & $k_{\text {cat }}\left(\mathrm{s}^{-1}\right)$ & $k_{\text {cal }} / K_{m}\left(10^{5} \mathrm{~s}^{-1} \mathrm{M}^{-1}\right)$ \\
\hline thermicin & $11.481( \pm 1.1)$ & $32299.58( \pm 30)$ & 2813.3 \\
Mutant L1-3 (deleted long loop) & $8.906( \pm 0.2)$ & $29976( \pm 20)$ & 3365.82 \\
Mutant L2-2 (deleted small loop) & $11.3045( \pm 1)$ & $32552.05( \pm 40)$ & 2879.56 \\
\hline
\end{tabular}

${ }^{a}$ Enzyme activity was assayed using a aceton-precipitated sample by the method of Wells et al. L-Gly-Pro-pNA (Sigma Chemical Co., St. Louis, Mo.) was the substrate

change in thermal factors correlates with the two published structures of psychrophilic proteins - citrate synthase (Russell et al., 1998) and malate dehydrogenase (Kim et al., 1999). For both citrate synthase and malate dehydrogenase, the thermophilic counterpart had significantly larger thermal factors than the psychrophile. It should be noted that in the case of citrate synthase, both of the structures were solved in the same laboratory using the same programs (Russell et al., 1998). Higher thermal factors for thermostable enzymes, as compared to mesophilic enzymes, have been seen in other cases as well (Yip et al., 1995). One interpretation of these observations is that the thermal factors are dominated by the dynamic component. Also, where structures are determined, thermophilic enzymes are more flexible than mesophilic enzymes at room temperature This explanation, however, is contradicted by experimental work, which demonstrates that protein flexibility decreases as the temperature decreases (Cao et al., 1998).

The dynamic component of thermal factors represents a degree of conformational flexibility, while the static component would reflect different protein conformations in each unit cell of one crystal. A recent publication by Zavodszky et al. suggests that thermophilic proteins are indeed more conformationallyrigid than mesophilic proteins at the same temperature.
Therefore, our observations could be explained by multiple conformations for thermophilic proteins at mesophilic temperatures. If this is true, then the high thermal factors that were observed for thermophiles are due to static rather than dynamic disorder. At room temperatures, thermophilic enzymes may be frozen into a number of slightly different conformations. The existence of multiple conformations of the enzyme could also explain why thermophilic enzymes are not functionally-active at mesophilic temperatures. Thermostability is a prerequisite for the successful application of enzymes in industrial processing. The industrial use of proteases in detergents or for leather processing requires that the enzyme be stable at higher temperatures.

In conclusion, the small loop in thermicin plays a critical role in thermostability; whereas, the large loop may be involved in catalysis. However, how the loops are mechanistically involved in the enzyme characteristics, and how well they are correlated to the various explanations in different thermostable enzymes, remains to be elucidated.

Acknowledgments This work was supported by grants from the Korea Science and Engineering Foundation through Bioproducts Research Center and Protein Network Research Center (2000-2-0607). 

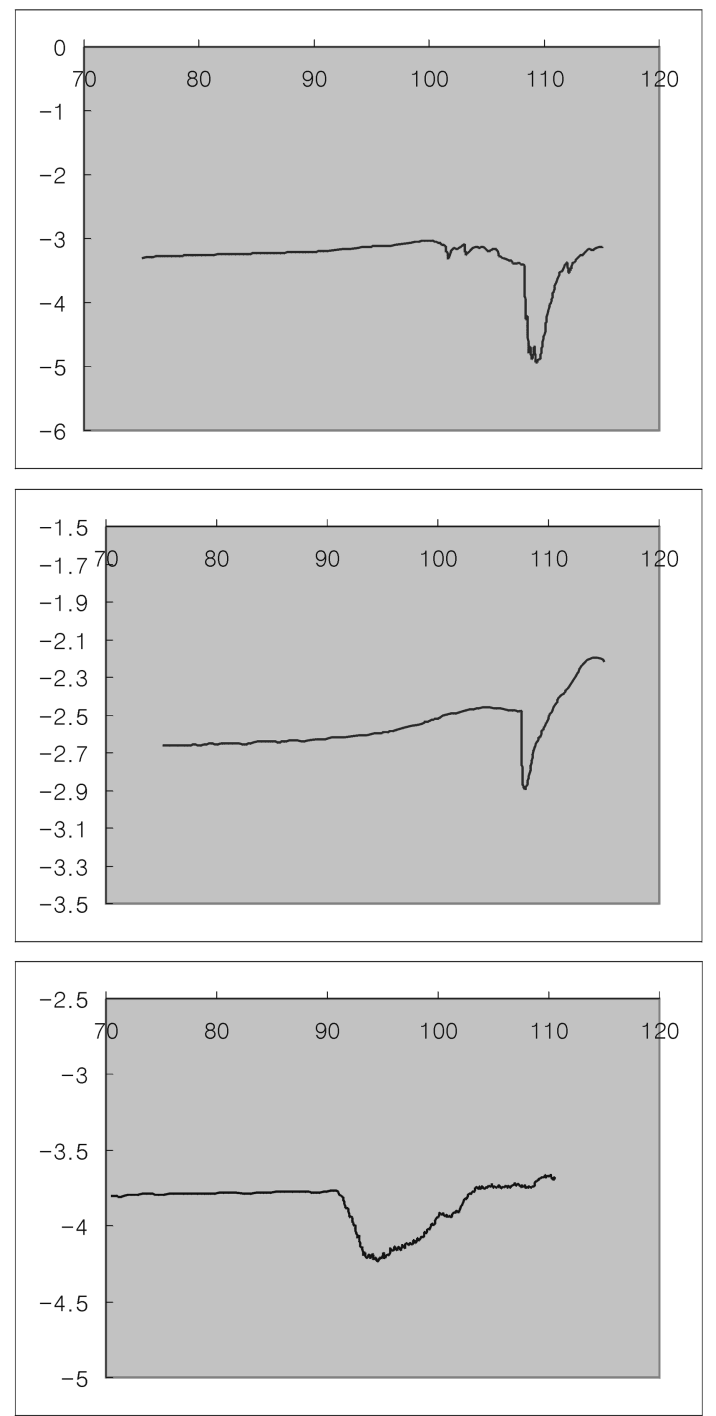

Fig. 5. Differential-calorimetric scanning of thermicin. The purified proteins, at a concentration of $1 \sim 2 \mathrm{mg} / \mathrm{ml}$ in $10 \mathrm{mM}$ sodium acetate, $\mathrm{pH} 5.0$, were heated at a constant rate of $2^{\circ} \mathrm{C} /$ min up to $125^{\circ} \mathrm{C}$. Top, middle, and bottom plates indicate those for native thermicin, mutant thermicin L1-3 (deleted long loop), and mutant thermicinL2-2 (deleted small loop), respectively. Xand Y-axis indicate temperature $\left({ }^{\circ} \mathrm{C}\right)$ and heat flow $(\mathrm{W} / \mathrm{g})$, respectively. The inverted peaks indicate that at this temperature, heat was consumed to denature the proteins.

\section{References}

Argos, P., Rosseman, M. G., Gsau, U. M., Zuber, H., Frank, G. and Tratschin, J. D. (1979) Thermal stability and protein structure. Biochemistry 18, 5698-5703.

Bacon, D. J. and Anderson, W. F. (1988) A Fast Algorithm for Rendering Space-Filling Molecule Pictures. J. Mol. Graph. 6, 219-220.

Cao, W., Lu, J., Welch, S. G., Williams, R. A. and Barany, F. (1998) Cloning and thermostability of TaqI endonuclease isoschizomers from thermus species SM32 and Thermus filiformis TOKGA1. Biochem. J. 333, 425-431.

Chan, M. K., Mukund, S., Kletzin, A., Adams, M. W. W. and Rees, D. C. (1995) Structure of a hyperthermophilic tungstopterin enzyme, aldehyde ferredozin oxidoreductase. Science 267, 1463-1469.

Daniel, R. M., Cowan, D. A., Morgan, H. W. and Curran, M. P. (1982) A correlation between protein thermostability and resistance to proteolysis. Biochem. J. 207, 641-644.

Day, M. W., Hsu, B. T., Joshu-Tor, L., Park, J., Zhou, Z. H., Adams, M. W. W. and Rees, D. C. (1992) X-Ray crystal structure of the oxidized and reduced forms of the rubredoxin from the marine hyperthermophilic archaebacterium Pyrococcus furiosus. Protein Sci. 1, 14941507.

Eijsink, V. G. H., Vriend, vanden Burg, G. B., vander Zee, J. R. and Venema, G. (1992) Increasing the thermostability of a neutral protease by replacing positively charged amino acids in the N-terminal turn of $\alpha$-helices. Protein Eng. 5, 165-170.

Eriksson, A. E., Baase, W. A., Zhang, X. J., Heinze, D. W., Blaber, M., Baldwin, E. P. and Matthews, B. W. (1992) Response of a protein structure to cavity creating mutations and its relation to the hydrophobic effect. Science 255, 178183.

Fields, P. A. and Somero, G. N. (1998) Hot spots in cold adaptation: localized increases in conformational flexibility in lactate dehydrogenase A4 orthologs of Antarctic notothenoid fishes. Proc. Natl. Acad. Sci. USA 95, 11476-11481.

Fleming, T. and Littlechild, J. (1997) Sequence and structural comparison of thermophilic phophoglycerate kinases with a mesophilic equivalent. Comp. Biochem. Physiol. 118A, 439451.

Imada, K., Sato, M., Tanaka, N., Katsube, Y., Matsuura, Y. and Oshima, T. (1991) Three-dimensional structure of a highly thermostable enzyme, 3-isopropylmalate dehydrogenase of Thermus thermophilus at $2.2 \AA$ resolution. J. Mol. Biol. 222, 725-738.

Kim, Y. K., Choi, I. G., Nam, W. and Yu, Y. G. (2000) Identification of a mature form and Characterization of Thermostability of a Serine-type Protease from Aquifex pyrophilus. J. Biochem. Mol. Biol. 33, 493-498.

Kim, S. Y., Hwang, K. Y., Kim, S. H., Sung, H. C., Han, Y. S. and Cho, Y. (1999) Structural basis for cold adaptation. J. Biol. Chem. 274, 11761-11767.

Kraulis, P. J. (1991) MOLSCRIPT: A Program to Produce Both Detailed and Schematic Plots of Protein Structures. J. Appl. Crystal. (1991) 24, 946-950.

Laskowski, R. A., MacArthur, M. W., Moss, D. S. and Thornton, J. M. (1993) PROCHECK: a program to check the stereochemical quality of protein structures. J. Appl. Crylstallogr. 26, 47-60.

Lim, W. A. and Sauer, R. T. (1989) Alternative packing arrangements in the hydrophobic core of 1 repressor. Nature 339, 31-36.

Matsumura, M., Becktel, W. J. and Matthews, B. W. (1988) Hydrophobic stabilization in T4 lysozyme determined directly by multiple substitutions of Ile 3. Nature 334, 406-410.

Mitchinson, C. and Wells, J. A. (1989) Protein engineering of disulfide bonds in subtilisin BPN'. Biochemistry 28, 4807-4815.

Nakamura, S., Tanaka, T., Yada, R. Y. and Nakai, S. (1997) Improving the thermostability of Bacillus stearothermophilus neutral protease by introducing proline into the active site 
helix. Protein Eng. 10, 1263-1269.

Panasik, N, Brenchley, J. E. and Farber, G. K. (2000) Distributions of structural features contributing to thermostability in mesophilic and thermophilic a/b barrel glycosyl hydrolyses. Biochim. Biophys. Acta 1543, 189-201.

Perutz, M. F. and Raidt, H. (1975) Stereochemical basis of heat stability in bacterial ferredoxins and in hemoglobin A2. Nature 255, 256-259.

Russell, R. J. M., Ferguson, J. M. C., Hough, D. W., Danson, M. J. and Taylor, G. L. (1997) The crystal structure of citrate synthase from the hyperthermophilic archaeon Pyrococcus furiousus at $1.9 \AA$ resolution. Biochemistry 36, 9983-9994.

Russell, R. J. M., Gerike, U., Danson, M. J., Hough, D. W. and Taylor, G. L. (1998) Structural adaptations of the cold-active citrate synthase from an Antarctic bacterium. Structure 6, 351361.

Sali, A. and Blundell, T. L. (1993) Comparative protein modeling by satisfaction of spatial restraints. J. Mol. Biol. 234, 779-815.

Sandberg, W. S. and Terwillinger, T. C. (1991) Influence of interior packing and hydrophobicity on the stability of a protein. Proc. Natl. Acad. Sci. USA 88, 1706-1710.

Scandurra, R., Consalvi, V., Chiaraluce, R., Politi, L. and Engel P. C. (1998) Protein thermostability in extremophiles. Biochimie 80, 933-941.

Shortle, D. (1992) Mutational studies of protein structures and their stabilities. Q. Rev. Biophys. 25, 205-250.

Sippl, M. J. (1993) Boltzmann's principle, knowledge-based mean fields and protein folding. An approach to the computational determination of protein structures. J. Compu.-Aided. Mol. Des. 7, 473-501.

Takagi, H., Hirai, K., Maeda, Y., Matsuzawa, H. and Nakamori, S. J. (2000) Engineering subtilisin E for enhanced stability and activity in polar organic solvents. J. Biochem. 127, 617-625.

Takagi, H., Takahashi, T., Momose, H., Inouye, M., Maeda, Y., Matsuzawa, H. and Ohta, T. (1990) Enhancement of the thermostability of subtilisin $\mathrm{E}$ by introduction of a disulfide bond engineered on the basis of structural comparison with a thermophilic serine protease. J. Biol. Chem. 265, 6874-6878.

Teplyakov, A. V., Kuranova, I. P., Harutyunyan, E. H., Frommel, C. and Hohne, W. E. (1989) Crystal structure of thermitase from Thermoactinomyces vulgaris at 2.2 A resolution. FEBS Lett. 244, 208-212.

Urfer, R. and Kirschner, K. (1992) The importance of surface loops for stabilizing an eightfold a/b barrel protein. Protein Sci. 1, 31-45.

Vogt, G., Woell, S. and Argos, P. (1997) Protein thermal stability, hydrogen bonds, and ion pairs. J. Mol. Biol. 269, 631-643.

Vriend, G. and Sander, C. (1993) Quality-Control of Protein Models-Directional Atomic Contact Analysis. J. Appl. Crystallogr. 26, 47-60.

Wallon, G., Kryger, G., Lovett, S. T., Oshima, T., Ringe, D. and Petsko, G. A. (1997) Crystal structure of Escherichia coli and Salmonella typhimurium 3-isopropylmalate dehydrogenase and comparison with their thermophilic counterpart from Thermus thermophilus. J. Mol. Biol. 266, 1016-1031.

Wells, J. A. and Powers, D. B. (1986) In vivo formation and stability of engineered disulfide bonds in subtilisin. J. Biol. Chem. 261, 6564-6570.

Yip, K. S., Stillman, T. J., Britton, K. L., Artymiuk, P. J., Baker, P. J., Sedelnikova, S. E., Engel, P. C., Pasquo, A., Chiaraluce, R. and Consalvi, V. (1995) The structure of Pyrococcus furiosus glutamate dehydrogenase reveals a key role for ion-pair networks in maintaining enzyme stability at extreme temperatures. Structure 3, 1147-1158.

Yutani, K., Ogasahara, K., Tsujita, T. and Sugino, Y. (1987) Dependence of conformational stability on hydrophobicity of the amino acid residues in a series of variant proteins substituted at a unique position of tryptophan synthase a subunit. Proc. Natl. Acad. Sci. USA 84, 4441-4444.

Zavodszky, P., Kardos, J., Svingor, A. and Petsko, G. A. (1998) Adjustment of conformational flexibility is a key event in the thermal adaptation of proteins. Proc. Natl. Acad. Sci. USA 95, 7406-7411. 